\title{
A Research on Cultural Differences Impact on Sino-US Business Negotiation
}

\author{
Ke Gong \\ Foreign Languages Department, Shandong Jiaotong University, Jinan, China \\ Email: karen999568@hotmail.com
}

\begin{abstract}
As a part of communication, cultural differences affect business negotiation deeply. In a globalizing world today, with international business happened frequently, cultural differences bring influence to communication, any misunderstanding of it may directly affect the business. Therefore, it makes sense for the countries of different cultural backgrounds to understand each other. With the entry into the 21st century and China's access to the WTO, Sino-U.S. trade and economy has developed rapidly, and it is necessary for the negotiators from two countries to understand the cultural differences and make full use of the beneficial strategies.
\end{abstract}

Index Terms - cultural difference, Sino-U.S. business, strategy

\section{INTRODUCTION}

Nowadays, with the development of the world economy and globalization, more and more international business frequently happened in different countries. As a result, business becomes more and more intercultural. Today, as an important part of intercultural communication, negotiation has received increasing attention. With the rapid development of globalization and China's prosperous economy day by day, especially with its success of holding the Olympic Games, China, the biggest developing country in the world, has become a major business partner of America. China and the United States, the two largest cultural groups and trading countries, will unavoidably encounter cultural differences. Today, as business relations between China and the United States grow, as well as the frequency of business negotiations among the people from those two countries. Under such circumstance, the business between China and the United States has developed in a rapid rate, more and more negotiations carried out between the two countries. The cultural differences bring not only the challenges, but also the opportunities to the trade between the two countries. This article focuses on the study of cultural differences between China and the United States. It provides the ways to deal with the Sino-U.S. cultural difference, which correctly appears in the negotiation process, thus giving some reasonable suggestions that enable the negotiation between two sides carry on smoothly.

Lisa Hope Pelled has pointed out in his theory: "Negotiation is a process of joint decision making among people with different preferences." A formal definition of negotiation is the research content of psychology, politics, which plays an important role in human cooperation actions. As an important form of communication, intercultural negotiation varies from culture to culture. The business negotiation process is generally more complex because cultural differences may influence effective communication.

\section{Present Situation OF Sino-U.S. Business Negotiation}

Since the bilateral business has happened more and more frequently, there is no doubt that international trades between those two countries attract worldwide attention. How to melt different cultural context between China and U.S. in the international business negotiations also learned by the two countries. Along with the frequency of Sino-U.S. business trade, some complex factors happened during the negotiation. As a result, the conflicts in the negotiation process between the two countries increasing intensely, becoming the main obstacles of economy and trade now.

Cultural difference is the foundation of cross-cultural business and it is the key point of Sino-U.S. negotiation. The Sino-U.S. cultural difference lies in the performance of the language and nonverbal communication. Because cultural differences affect on Sino-U.S. negotiation in all aspects, person with a lack of sensitivity often like to use their own cultural model as a basic method to evaluate other people's culture, ideas and customs. It is likely to lead to culture shock. Therefore, for Chinese and the Americans in business negotiations, it is necessary to strengthen the sensitivity of cultural differences.

\section{The ANALYSIS OF AFFECTING FACTORS}

\section{A. Verbal and Non-verbal Factors Affecting Sino-U.S. Business Negotiation}

Verbal differences mostly refer to language differences. For example, in the verbal communication, people from different countries may not pay attention to the differences that reflected in the meaning or connotation of the words. 
As Huchao put in his book intercultural communication, "Language is the carrier of culture; what is more, it is the main form of expression and means of dissemination of culture." Therefore, when the people from different cultures communicate with each other, verbal differences affect on how they send and receive their messages.

Because of cultural differences, the same language in the U.S. and Chinese may cover the different connotations. China is a civilized country that is serious about the etiquette. There were many modest and self-abasement words admired in spoken language since ancient time. When received praise from others, Chinese people are generally modest. Another point in the business conversation is to use appellation to show respect to another in China. On the other hand, American people always advocate equality and they are more straightforward. For instance, in the work place, it is common that younger generation call the elder or even their boss's name. According to praise, the American will accept the praise immediately and show their thanks to them.

Referred to nonverbal communication, people may base their judgment on an evaluation of facial expressions, gestures, eye contact, greeting behaviour, etc. In short, nonverbal signals are silent language symbols for the information exchange. Although nonverbal communication tends to enhance and support language, sometimes they may minimize or even contradict a language.

1) Gesture

The gesture used in business negotiation is to stress a certain viewpoint or strengthen one's tone of language. Appropriate use of gesture will attract counterpart's attention, at the same time, help a good negotiator to express his own anger and displeasure. Similarly, potential meanings contained by gestures in different culture are also different. In business negotiation, successfully distinguish the gesture language as well as the internal meaning within them is an art. As for Sino-U.S. negotiation, Chinese dislike the following gesture: "Extend the hand to the called person with the palm of the hand upward, makes a fist swings with the index finger around." which the Americans usually express to call somebody come. It is also impolite in China when a businessperson from U.S. wants to emphasize a point in a discussion, he may pound his fist on the table and underline his statements with staccato drumming on the table. Another example is when use their fingers in counting 5, Americans, start with the index finger, go on to the little finger, and count the thumb last, that is different from Chinese habits.

\section{2) Facial Expression}

The human beings are sentimental animals, so the emotion outpouring is a person's natural disposition. For example, in Chinese, the phrases "beam with smiles" and "bristle with anger" are the sentiment reveal on the facial expression. Similarly, the appropriate facial expression displays in the appropriate time may also promote the language expression. However, even if is the most basic facial expression - smile, also has different meaning in the different cultural human relations.

As for Americans, related to smile is the laugh. Americans regard laugh as deepest emotion comes from the body and mind. In the negotiation process, the American think that the smile is a symbolic of enthusiasm and friendship, so businessmen in America like to beam with smiles. Compared to Americans, Chinese people are more cautious of smile. Besides the expression of cheerful emotion, the Chinese also use smile to conceal their tension, embarrass, anger when necessary. As for Chinese businesspersons, they usually avoid optional smile, which means unserious attitude in negotiation. What's more, smile is to change a topic or exaggerate the atmosphere in the negotiation process.

Another important facial expression in business negotiation is silence. The stop of the conversation regarded as deep consideration for the Chinese people. On the other hand, the majority of Americans felt irritable and nervous to such long silence.

To make a better understanding, it requests businessperson between two countries to be good at watching people's every mood carefully in the negotiation. This will give a hand to catch the accurate emotional information the opposite party hide behind their facial expression.

\section{3) Eye Contact}

"The eyes are the windows of the mind, even if the look is written in water, it can launch thousands of information, express several of emotion and intention." (Yu Muhong, 2005, p.48)

From the former expressing, we can find the eye could transmit and express the exquisite feeling of human. Studies show that an individual tends to make eye contact with others more frequently if they approve of their idea. In general, during conversation people look at each other between 30 and 60 percent of the time. If their eye contact lasts for more than 60 percent, they are probably more interested in each other. For an instance, if they are lovers or arguers.

However, the expression of eye is irrevocable due to different culture or human communication. Rules governing eye contact are different in different cultures, and that differences can make people feel uncomfortable. People comment that men from the U.S. are cold and do not know how to establish eye contact. For example, in U.S., it is customary to look at the speaker's mouth when listening but make occasional eye contact with the listener when speaking. In China, however, it is opposite.

Under certain circumstances, eye contact is better than words. In business negotiation, the Americans thought a person who dares to face up the opposite party with eye contact as honest and straightforward, on the other hand, a person avoid eye contact is regarded as not interested at the table, this is so-called "Not trust a person who can't look you in the eyes" in American. In a word, it is impolite to stare at the opposite party when negotiation happened, but it 
may also regarded as distrust, or even bring bad impression if we talked at the table without eye contact. Therefore, businesspersons between China and the U.S. should consider the eye contact carefully in business negotiation.

4) Greeting Behavior

Greeting behavior and send-off etiquette are important parts of the nonverbal language in business negotiation. Greeting behavior creates an opportunity to start a good relationship with the other party from every beginning and the send-off etiquette may lay a smooth path for future cooperation.

When you meet your counterparts, it is important to wear formal dress. In dress code, Americans usually dress according to location and type of business. For example, visitors usually wear a suit and tie to the first meeting with a new contact. On the other hand, In China, suit, white shirt, conservative tie for men and conservative suit or dress for women.

Handshake is another important factor in greeting. A firm handshake gives the impression of confidence and shows the person is glad to meet you. The handshake is the most commonly used behavior on the first meeting, it also serves as generally international courtesy. The handshake is simply, but this small movement is actually relate to individual and company's image, sometimes affects the negotiations success. The Chinese people often shake hand while saying "hello". In his or her opinion, handshake at the first time usually means roping somebody's hand, generally cannot be overweight. However, as for Americans, handshake in the meeting should with power, grasp too lightly is considered as weak or lack of confident. For Americans there are some common rules: female should first extend a hand to male at the meeting; owner asking for handshake of their guests. Above rules should attract negotiator's attention as a greeting behavior.

\section{B. $\quad$ Other Cultural Factors Affecting Sino-U.S. Business Negotiation}

\section{1) Customs}

Just as a saying goes, "Custom is the great guide of human life". Knowing the customs of a country is prerequisite to understand the soul of that country and its people. Due to the differences of cultural background and the way of being educated, there is great difference between China and the U.S. in customs. These differences somewhat restrict people's action in certain area, such as business, speech, festival.

2) Values

China and U.S. hold different values due to the influence of different regions and political system. Chinese attach great importance to collectivism while the Americans praise individualism. The difference in value leads to other differences. For example, China advocates harmony and unification while the U.S. prizes for seeking self-value and self-honor.

3) Concepts

Thinking influenced by culture and other element. There is big difference on the way of thinking between China and America. For example, the Chinese's way of thinking is visual, intuitive and composite, while American's way of thinking is individual, nonfigurative and idiographic. Chinese's dialectical thinking was well interpreted by "the Golden Mean", in negotiation strategy, which tends to seek compromise and balance. Well, American's logic thinking is materialized on exploiting and innovation. They like to analyze the essence characteristics of things.

\section{STRATEGIES FOR SINO-U.S. BUSINESS NEGOTIATION}

As I illustrated above, we've found the cultural differences are really existed in the negotiation between the two countries with different cultural backgrounds. As a result, Great concentration should be made on the beneficial strategies for the Sino-U.S. business.

\section{A. Accurate Language Strategy}

In order to advance its national interest, China carries out practical policy to the outside world. Since language serves as an important tool in international communication, it is necessary for China to use it in an accurate way in Sino-U.S. negotiation. When negotiate with the U.S. counterpart, Chinese traders should adopt practical language strategy. That is, in the Sino-U.S. negotiation process, use language as accurate as possible, and show each part's opinion straightforward. When negotiators of both sides come across different ideas, it is wise to argue in a calm way. It is also important for Chinese businesspersons to avoid using such as "possibly", "perhaps" or other ambiguous words as reply to their American counterpart. At the same time, the expression should stress firmly without any reluctance of saying "no" when there is no agreement reached in the negotiation. It is important to tell opposite party our own manner and thought explicitly.

\section{B. Win-Win strategy}

The negotiations should not be zero and gambling, but long process that both sides seek the common ground step by step until obtain a win-win result with double satisfaction. Win-Win situation is the successful outcome. Both sides feel that they have received a fair deal and walk away satisfied. So they will get chance to do business again in the future. In Sino-U.S. negotiation, both sides should fit into different negotiation phases, adjust the way of communication and try to consider the common interests. Since Americans regards negotiation as solving problems through "give and take" 
based on respective strengths. It is wise that China obtain win-win strategy with domestic development. As China develops rapidly and stead headway is made in China-U.S. cooperation, more and more Americans will understand and trusting with great interest in Sino-U.S. negotiation.

\section{Harmonious Environment Strategy}

Cultural environment can influence the way in which persons perceive and approach certain key elements in the negotiation process. Knowledge of these cultural differences may help negotiators to better understand and interpret their counterpart's negotiation behavior and find ways to bridge gaps. It is advisable that Chinese negotiators should first show their respect to the different culture and customs of their American counterparts, for example, U.S. negotiators tend to talk to the specific clause directly in negotiation process, so Chinese sides could put the clau se at the beginning of the negotiation process to create a fair atmosphere. This will also give a hand to make American negotiators feel being respected, in return, they will also show expect to different behaviors in Chinese sides. Furthermore, understanding leads to trust, so both sides will achieve their outcome in such harmonious environment.

\section{Time Efficiency Strategy}

American does prefer speedy negotiations and get annoyed with too much extraneous socializing or postponement. They are used to cutting deals short just to save time. In America, negotiators usually make decision on the facts. They do not play favorites. On the other hand, decision-making process in China is usually ineffective. This is because most Chinese companies have bottom-up decision-making system, which involves many people in decision-making; they also like to socialize counterparts as basic courtesy. Knowing that culture difference, China should observe the principle of "business is business", take use of the time efficiently in the negotiation process.

\section{CONCLUSION}

With the rapid development of international business and intercultural communication, the China and the U.S. urgently need to understand cultural differences between them to carry out negotiation. The previous research in this article leads to some conclusions.

China and the U.S. are two countries with their own patterns in negotiation due to different cultural background, either pattern has its advantages and disadvantages. It is essential to show respect to each culture. At present, as powerful and insidious force in communication, cultural difference often exists visibly or invisibly in intercultural business. As a result, conflicts and misunderstandings are unavoidable in international negotiation. As a professional negotiator, it is our contention to enhance sensitivity to cultural differences through the way of using accurate language, adopting win-win strategy, avoiding negative concept.

Thus, if negotiator fully understand and properly get the way to deal with cultural differences, the negotiating process will certainly go smoothly. Since China has entered into the WTO, the opportunity for Chinese businessperson to cooperate with American partners has increasing dramatically. The discussion above will help Sino-U.S. negotiation achieve win-win outcome.

Because the article is based on the large sum of facts and evidence, it is believed that this article will have certain influence on negotiators and help Sino-U.S. business relationship develop in a more harmonious way.

\section{REFERENCES}

[1] Hu Chao. (2004). International communication. Beijing: Foreign Language Teaching and Research Press.

[2] Liu Yuan. (2004). International Business Negotiation. Beijing: University of International Business and Economics Press.

[3] Steyn. (2004). Cross-culturally negotiation. New York: People Dynamics Press.

[4] Richard W. Brislin, Tmoko. (1994). Intercultural Communication Training: An Introduction of Business Negotiation. California: Calif Publication.

[5] Varner Linda Beamer. (2002). Intercultural communication in the Global Workplace. Shanghai: Shanghai Foreign Language Education Press.

[6] William Stallings with contribution by Richard Van Slyke. (2001). Business data communication. London: Prentice Hall Press.

[7] Yu Muhong. (2005). Business English Negotiation. Beijing: Foreign Language Teaching and Research Press.

Ke Gong was born in Jinan, China in 1980. She received her M.A. degree in Shandong Normal University, China in 2009.

She is currently a lecturer in the School of Foreign Languages, Shandong Jiaotong University, Jinan, China. Her research interests include Business English and English Teaching. 